\title{
Local government research into a 'hidden' issue
}

\author{
Katherine Wright ${ }^{\mathrm{a}}$ \\ ${ }^{a}$ Community Planning and Development, City of Boroondara, \\ katherine.wright@boroondara.vic.gov.au
}

\begin{abstract}
There are increasing concerns emerging through research, demographic and service information about the marginal position of older women who lack resources and support for secure housing. Questions arise about the impact this has on their health and wellbeing as they age. In response, the City of Boroondara, with the support of Monash University, undertook local research during 2011-12 to explore the experiences and issues that place single, older women (55 years and over) at risk of homelessness or that lead to homelessness. As the City of Boroondara is an affluent municipality, many social problems are 'hidden'. Recruiting women to participate in the research was difficult. There were also issues in accessing supporting data from local organisations and Victorian and Australian Government departments. This paper will discuss the challenges in undertaking research into a 'hidden' issue at the local government level. The paper will also describe the key findings and how these will be used to inform the development of local policies relating to positive ageing, health and wellbeing, and housing. It will also discuss the implications for services providers.
\end{abstract}

\section{Introduction}

The City of Boroondara is located in the inner eastern suburbs of Melbourne, between five and 10 kilometres east of the Melbourne CBD. The municipality is, generally speaking, considered an affluent area. In 2011, the median weekly household income was $\$ 1,893$ compared to $\$ 1,333$ in Greater Melbourne (ABS 2013a), and the median house price was $\$ 1,250,000$ compared to $\$ 492,500$ in Greater Melbourne (Swinburne University of 
Technology 2013). The municipality was also second highest ranked of all Victorian local government areas on the Australian Bureau of Statistics' Index of Relative Socio-economic Disadvantage in 2011 (ABS 2013b).

Within the municipality, many problems facing local marginalised groups can be effectively 'hidden' from the community and funding bodies through the obfuscation of socio-economic indicators of disadvantage within general measures of affluence. In 2010, the City of Boroondara began local research into a hidden social issue: homelessness among older women. The project came about through anecdotal reports of an increase in the number of older women seeking housing assistance in the municipality. The reports indicated that older women were facing homelessness for a range of reasons, including the death of a spouse, reductions in pension income, and elder financial abuse (City of Boroondara 2010, p. $6)$.

The research was undertaken as the City of Boroondara has an ageing population, which may result in greater numbers of elderly women falling into homelessness, and local agencies were not well equipped to deal with growing housing demand for these individuals. There were also no clear solutions for preventing this new group from falling into homelessness for the first time.

The research aimed to provide Council, local service providers and the community with evidence based information about the circumstances of older women who are homeless or at risk of homelessness. This information could then be used by Council and service providers to inform policy, planning and service delivery in relation to this group, now and into the future.

This paper provides an overview of the background, methodology and findings of the third stage of the research project: 'health and housing: older women on the margins'. It also discusses the challenges and benefits of undertaking research into hidden issues at the local government level. The recommendations arising from the research and for undertaking research into a hidden issue are also identified.

\section{Background}

In Australia, there are increasing concerns emerging through research, demographic and service information regarding homelessness among older women. There are also limited policy responses and research into this issue at present. The following section provides a brief overview of the three stages of the research undertaken by the City of Boroondara into 
this issue. It also provides a brief overview of the policy context in which this research was developed and of recent Australian research.

\section{City of Boroondara}

The City of Boroondara began research on homelessness among older women in 2010. The research was undertaken in response to anecdotal reports of an increase in the number of older women seeking housing assistance in the municipality. The research comprised three stages as described in Figure 1.

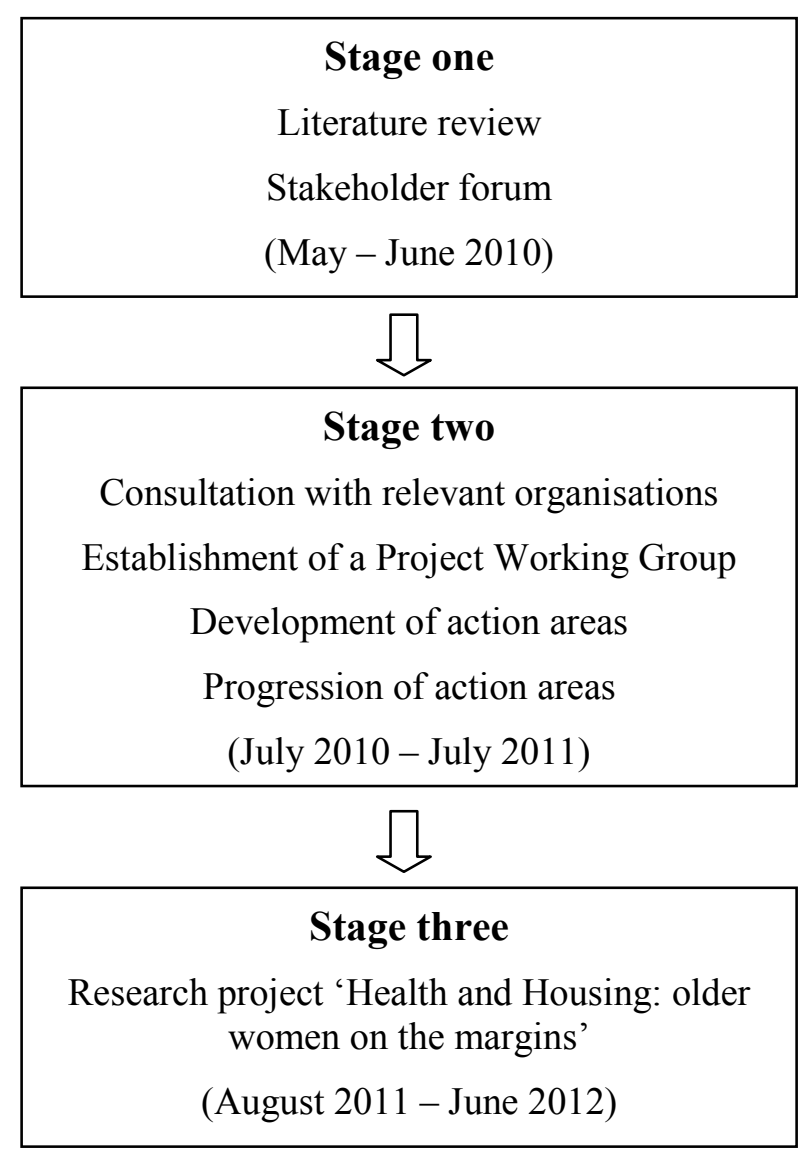

Figure 1: The three stages of the City of Boroondara research project on homelessness among older women.

Stage one

Stage one of the research was undertaken in partnership with the Salvation Army EastCare, which provides housing information, support and referral services to residents of 
the City of Boroondara. It involved a literature review of local, national and international work on the causes of, and trends in homelessness as experienced by older women. It also included a forum in June 2010 to inform key stakeholders about the findings of the preliminary research, and to consult on the experience of other organisations with the issue.

Stage two

Stage two of the research involved further consultation and development. A Project Working Group was established in November 2010 following consultation with key organisations that participated in the forum and those identified through subsequent planning. Representatives included support services, housing assistance providers, community health services and peak bodies. The purpose of the Project Working Group during stage two was to:

- consider the information and actions gathered from the literature review, the stakeholder forum and subsequent consultations

- identify and develop action areas and partnerships to progress work

- identify potential sources of funding for future work.

The Project Working Group identified the following five key areas for future work: data collection, advocacy, community education, information resources and research. A data collection tool was developed during this stage and used by local services and Council in mid-2011. The purpose of the tool was to assist in identifying the number of women aged 45 years and over who were homeless or at risk of homelessness in the City of Boroondara.

\section{Stage three}

Stage three of the research project, 'health and housing: older women on the margins', built on the work from stage two and progressed areas for research that would inform local community and service responses. The focus of the research was on single, older women, rather than older adults in general, as this group were considered particularly vulnerable to homelessness due to a range of drivers including low or no income, lack of superannuation, lack of equity in housing, lack of education and qualifications, and lower-paid work (City of Boroondara 2010, p. 3). There are also limited housing options to meet the short and longerterm needs of older women, as accommodation such as boarding houses are considered unsafe and rising housing and rental costs connected to the gentrification of the municipality makes housing unaffordable. 


\section{Policy context}

The Australian and Victorian Governments and the City of Boroondara all have policies on homelessness as follows:

- The Australian Government's white paper on homelessness, The Road Home: A National Approach to Reducing Homelessness, identifies national responses to the needs of particular groups within the homeless population (Australian Government 2008).

- The Victorian Government's Homelessness Action Plan 2011-15 supports innovative approaches to homelessness, investigating preventative and early intervention models, and allocating resources when and where they are most needed (Victorian Government 2011).

- The City of Boroondara's Social Housing Policy 2008-11 focuses on retaining and increasing the supply of social housing to meet the needs of low income and disadvantaged residents, as well as those who are either homeless or at risk of homelessness (City of Boroondara 2008).

Both the Australian and Victorian Government's policies identify older people, but not older women, as a target group for future work. The City of Boroondara's policy similarly does not identify older women as an at risk group.

\section{Recent research}

As noted earlier, a comprehensive review of local, national and international literature focusing on the causes of, and trends in homelessness in relation to older women was undertaken during stage one of the project in 2010. The literature review found that there are substantial gaps in knowledge around the issues confronting older homeless women. It also found that there was a clear need for more qualitative research on the causes and responses to older women's homelessness, particularly as the number of older women is growing and the demand for affordable accommodation is likely to increase (City of Boroondara 2010, p. 5).

Since the stage one literature review, a number of Australian research projects relevant to this subject have been undertaken by community based organisations and peak bodies. This research was undertaken primarily in response to growing concerns about meeting the demands for housing by women, older adults or older women. The three most relevant projects are: 
It could be you: female, single, older and homeless aimed to 'investigate the life trajectory of women who become or remain homeless past the age of 45 years, in order to interrogate the definition of homelessness that determine government homeless policy' (McFerran 2010, p.17). The research, which included interviews with 31 women in New South Wales who had experienced homelessness and were 45 years and older, found that being female, older and single is to be at housing risk. The report made a number of recommendations, suggesting that a gendered analysis of housing, homelessness and ageing policy was needed, and that more affordable and appropriate single person housing for single older women was needed (McFerran 2010, p. 4).

Ageing in what place? The experiences of housing crisis and homelessness for older Victorians (Westmore \& Mallett 2011) aimed to examine older individuals' pathways into housing crisis and homelessness in Victoria. The report made a number of recommendations including the need to simplify the service system, fund financial counselling and support for older people in housing stress, develop national and state housing policies for older people, and educate older people, service providers and the public about services available to assist older people who are homeless or at risk of homelessness.

Home truths: impacts of housing security on women across the life course (Anglicare Sydney 2011) examined quantitative data from Anglicare Sydney's emergency relief client database and qualitative data via in-depth interviews and focus groups. The research found that half of the women who were renting privately or publicly aged over 50 years between July 2007 and March 2011 were experiencing significant rental stress. The research also found that older women who were living alone were more likely to live in insecure housing and to live in households with lower incomes. In addition, single older women were also more likely than older women in other family types to be dependent on the Newstart Allowance for their income (Anglicare Sydney 2011, pp. 32, 35).

\section{Aims}

The objectives of the research project were to:

- generate knowledge about the current and future levels of homelessness and risk of homelessness for older women in the Boroondara community

- identify the factors that contribute to older women becoming homeless or at risk of homelessness 
- identify issues relating to housing stress specific to older women from diverse communities, e.g. women from culturally and linguistically diverse (CALD) backgrounds

- identify issues relating to housing stress specific to older women with mental health problems or illnesses

- identify the pathways and tipping points to becoming homeless, or at risk of homelessness for older women

- identify how the service system and the community can respond to homelessness and the risk of homelessness among older women.

\section{Methodology and findings}

The Social Planning Unit at the City of Boroondara, and in particular the Social Planning Officer and the Coordinator Social Planning, were responsible for conducting the research. This included developing the project methodology, undertaking the data collection methods, analysing the information, and writing up the project outcomes. The City of Boroondara also initiated a working relationship and research partnership with the Healthy Ageing Research Unit (HARU) of the University of Monash for the project. A Masters of Community Psychology student also assisted in conducting the interviews and information analysis.

A range of data collection methods were used. This ensured that relevant demographic and service data, and the views of the community, service providers and older women were considered. It also assisted in raising awareness within the community about the project and the issue in general, as the data collection methods were widely promoted through Council's website, monthly magazine, libraries, customer service centres, newsletters and other relevant networks. The data collection methods employed and the findings for each method are described below.

\section{Project Working Group}

A Project Working Group considered the implications of the research findings for service providers, peak bodies and older community members. In particular, the role of the Project Working Group was to:

- reflect on the information emerging through the research 
- contribute to a local model for responding to older women who are homeless or at risk of homelessness

- contribute to the development of forward directions based on information arising from the research project

- progress the action areas developed in stage two of the research.

The Project Working Group also had input into the development of the research methodology and played a key role in the promotion and recruitment of older women to the interviews.

The key areas for future work, described below, were developed in conjunction with the Project Working Group.

\section{Profile of older women and housing issues}

A demographic profile of older women and related housing issues was developed to inform knowledge about the current and future levels of homelessness and risk of homelessness for older women in the municipality. The demographic profile included information about the types of housing in which older women live, how much they pay for their housing, and population forecasts. The housing profile included housing affordability measures, house and unit prices, information about the number of social housing dwellings, and public housing waiting list times. Other relevant Australian research on housing projections for older adults was also incorporated.

The key findings of the profile of older women and housing issues were as follows:

- There is predicted to be a large increase in the number of women aged over 55 years in the municipality between 2011 and 2021, with the number forecast to increase by 3,223 from 24,309 to 27,532 (Forecast.id 2011).

- One of the main risk factors contributing to homelessness among older women is living alone. In the City of Boroondara, women aged over 55 years are more likely than men to live in sole person and single-parent households, and the likelihood of living in a sole person household increases with age up to around 90 years (Australian Bureau of Statistics 2011).

- The National Housing Supply Council 2010 State of Supply Report projected that the ageing population (65 years and older) would grow from 19 per cent to 28 per cent of all Australian households between 2008 and 2028 (National Housing Supply Council 2010, p. xvi). While owner-occupier will remain the preferred tenure type, demand 
for private and public rental by older people nationally was predicted to increase from 146,200 to 321,400 for private rental, and from 86,500 to 189,800 for public rental over the same 20 year period. Forecasting by the Australian Housing and Urban Research Institute also found that by 2051 a significant drop in the number of older Australians that own their home outright is expected, from 78 per cent in 2006 to 55 per cent by 2051 (Bridge et al. 2011, p. 27).

- Affordable housing options for older residents in the City of Boroondara (whether they are looking to rent or to buy) are limited, with only 14 advertised rental properties affordable for people on Centrelink payments in June 2011. For this same quarter, there were no affordable one-bedroom properties available, effectively preventing sole person households from accessing affordable dwellings suited to their needs (Department of Human Services 2011a, p. 26).

- There is a lack of social housing in the City of Boroondara. In June 2010, there were 827 public housing dwellings and 78 community housing dwellings in the City (Department of Human Services 2011b).

- Waiting times for public housing can be long. In December 2011, there were 2,259 people on the public housing waiting list and an additional 396 people on the public housing transfer list in the Box Hill region (Department of Human Services 2011c).

\section{Service data requests}

To build knowledge about the current level of homelessness or risk of homelessness among older women, requests for service data were made to local, Victorian and Australian organisations providing services in the municipality. The data requested related to the number of single, older women who were accessing housing services or that had been identified by the services as being homeless or at risk of homelessness.

\section{Community survey}

In December 2011 a self-completion survey was mailed to 135 faith groups, Probus clubs and senior citizen clubs in the municipality. The survey was also promoted through Council's website and in the local paper, and distributed via email to relevant networks. The aim of the survey was to elicit community knowledge and experiences of older women and homelessness in the municipality. The survey included 13 questions and collected both qualitative and quantitative data. The survey also provided a way of raising awareness in the community about the issue. Forty-nine responses to the survey were received. 
The community survey found that over half (55.3 per cent) of the respondents thought homelessness was an issue for older women, while 6.4 per cent did not think it was, and 38.3 per cent were not sure. Only 10 of the respondents reported having contact either personally or through their community group, network or service with women in Boroondara that were homeless. When asked about their awareness of services available to assist older women, respondents showed a high level of awareness of health and medical services (71.4 per cent), social and support activities (65.7 per cent), and in-home support (65.7 per cent). However, only 37.1 per cent were aware of housing services.

These findings highlight the need to raise awareness about the issue within the community and about services available such as Housing for the Aged Action Group, the Salvation Army EastCare, and the Department of Human Services - including Centrelink.

\section{Qualitative interviews}

Semi-structured qualitative interviews were undertaken between December 2011 and February 2012 with 13 women that were recently homeless or at risk of homelessness. Participation in the interviews was promoted through local service providers, libraries, on Council's website, and in the local paper. Members of the Project Working Group also approached women accessing their services about participating in the research.

Women were eligible to participate in the interviews if they were single, were 55 years and older, lived or had recently lived in the City of Boroondara, and had experienced homelessness or had been at risk of homelessness in the last 12 months. Women were defined as being homeless in this research if they fell within one of the following three categories of homelessness as defined by Chamberlain and MacKenzie (2006, p. vii):

- Primary homelessness: people without conventional accommodation, e.g. living in streets, deserted buildings, improvised dwellings and parks.

- Secondary homelessness: people staying in boarding houses, people utilising emergency accommodation services such as the Supported Accommodation Assistance Program, and people with no secure accommodation staying temporarily with friends or relatives in private dwellings.

- Tertiary homelessness: people living in boarding houses on a medium to long-term basis, operationally defined as 13 weeks or longer. These people are considered homeless because their accommodation situation is below the minimum community standard for a small self-contained flat. 
Women were categorised as at risk of homelessness if they were currently housed, but their housing was insecure and they potentially faced homelessness due to limited alternative housing options available to them. This included women in private rental accommodation who were concerned their rental costs would increase, that their income could decrease, or that the property would be sold.

The purpose of the interviews was to understand the circumstances and issues that place single, older women at risk of homelessness or that lead to homelessness. An interview agenda guided the interviews and included key questions about the participants' experiences of homelessness or being at risk of homelessness, the factors they regarded as leading to their homelessness or risk thereof, and their experiences of services and support systems.

Interview participants also completed a demographic information sheet, with details about their age, income, source of income, rental or mortgage repayments, their current accommodation arrangements, how long they had lived in the municipality, country of birth, and level of education.

The interviews provided an in-depth understanding of the circumstances and issues that place single, older women at risk of homelessness or that lead to homelessness. The key findings of the interviews are summarised below:

- There was not a single tipping point that lead to homelessness. The women described complex life experiences over extended periods that contributed to a decline in their circumstances. In many ways the women could be described as typical, with the issues that contributed to their housing situations likely encountered by many women.

- Common challenges facing homeless or at risk women included mental health issues, complex and co-occurring health conditions, abuse, disrupted career paths, family relationship breakdowns, and the demands of caring.

- A key theme that emerged through the interviews was that of not seeking help due to the shame and stigma the women experienced, and also as a result of their negative self-perception and experiences in seeking help.

- Deteriorating health in general was common among the women as a result of their housing issues, and this impacted on their ability to work. Dislocation from family, friends and other networks also had a negative impact on their health and wellbeing and highlighted the importance of ageing in place.

- The lack of affordable and appropriate housing to enable women to remain in their communities as they age was identified as an issue. 
- The importance of recognising the diversity that exists among older women as a group was evident. For women of CALD backgrounds, this included limitations of the service system in understanding the importance of community and family connections and its connection to housing, and also for access to culturally relevant services.

- The women's connections to the service system varied, with seven of the interviewees classified as being at risk of homelessness managing the attendant housing issues by themselves. No characteristic differences between women who were managing on their own and women connected to the service system were identified. However, it appeared that the women who were managing issues themselves often sought out alternative and sometimes compromised living arrangements (e.g. share house, live-in carer, family members and cheap private rentals).

- When the interviewees faced an acute housing crisis, the women either self-referred to support services, or were referred by friends, support service providers such as Home and Community Care (HACC) or Camcare, or by Centrelink. The services to which the women were connected included housing providers, support services, Centrelink, legal aid, aged respite, allied health, support groups for health issues, general practitioners (GPs), libraries, and other support services.

- In some cases it was found that once the women had received housing assistance, there was a lack of follow up by the service providers to link to the women back into the community through services such as HACC, social support groups or allied health professionals.

\section{Real estate agents and funeral directors survey}

Real estate agents and funeral directors were identified as key businesses that may have contact with older women at vulnerable times of their lives when they may become homeless or at risk of homelessness. For example, when their partner dies they may not be able to make mortgage or rental repayments, or they may be given a notice to vacate and not know where to seek assistance with finding a new property.

In January 2012, a survey was mailed to 92 real estate agents and funeral directors with business addresses in the City of Boroondara. The aim of the survey was to gather information about whether people working in these businesses had experiences with older women who were at risk of homelessness. The survey included 10 questions and collected 
both qualitative and quantitative data. As with the community survey, this survey also aimed to raise awareness about the issue among these businesses. Five responses to the survey were received from real estate agents.

The low response rate may have been due to the timing of the survey, which was mailed out when real estate agents in particular may have been on leave. It may also indicate that real estate agents and funeral directors do not think homelessness among older women is an issue, and/or that they do not see that their services can play a role in responding to the issue. As no responses were received from funeral directors, it might indicate that they would not become aware of a client's risk of homelessness when providing services.

The survey of real estate agents found that:

- The respondents either thought homelessness was not an issue or were not sure if it was an issue.

- Only one respondent had contact with an older woman who was at risk of homelessness.

- Three of the respondents were aware of housing information, support and referral services.

- Four of the respondents noted that a directory of local services and advice lines would assist them to respond to older women who are at risk of homelessness.

- Two thought that information sheets that describe the issues and options would be useful.

As with the community survey, these findings highlight the need to raise awareness about the issue and provide information on where to seek help to businesses that are likely to come in contact with older women with housing issues.

\section{Community workshop}

Respondents to the community survey were invited to a workshop in mid-February 2012 to explore strategies which may assist older women to maintain secure housing and enhance social connections, and to flag strategies for the community and service providers to better respond to the issue of homelessness in older women. Five community groups participated in the workshop.

The community workshop participants identified the following actions that they thought could prevent homelessness among older women: 
- better information about services through community services such as neighbourhood houses or GPs

- health providers being more alert to social issues

- accessible health services for people on low incomes

- reduced waiting times for public health services

- promoting the message that 'it's ok to ask for help'

- more support systems and social groups

- education about services and social issues.

Preventative actions relating specifically to service system changes identified by the participants were:

- more housing options that are safe, accessible, secure and appropriate

- information sessions for health professionals about housing risks

- holistic case management

- coordinated services.

The findings of the community workshop emphasised the need for community education about the issues, where to seek help, and that it's ok to ask for help. The need for more affordable housing and the important role that health professionals can play in addressing the issue was also highlighted.

\section{Limitation}

The main limitation of the present study was the small sample size. While the interviews were able to generate some rich and diverse data, it is not possible to generalise the findings to all women over the age of 55 who are homeless or at risk of homelessness.

\section{Discussion}

The findings of this research demonstrate the value of undertaking research into social issues at the local government level. This section discusses the challenges and benefits of undertaking this type of research, and also discusses the recommendations arising from this research. 


\section{The challenges in researching a hidden issue}

This research identified a number of challenges in researching a hidden issue at the local government level. These included difficulties in recruiting participants, accessing supporting data, and having the specialist knowledge and officer time to complete the research. These challenges are briefly discussed below.

- The process of identifying older women to participate in the interviews was challenging because, as has been asserted throughout this paper, the issue is largely hidden. This meant that, due to lack of awareness about the issue, women may not have been aware that they would be considered homeless or at risk of homelessness for the purposes of the research. The relative social isolation of the target group may have also reduced their awareness of, and access to the research process.

- The shame and stigma of admitting to experiencing a hidden social problem in an affluent municipality may also have stopped women from participating in the research.

- While services were aware of women who would have been eligible to participate in the research, it was not always appropriate to approach them as they were in the midst of a crisis.

- Accessing data from service providers to support the qualitative findings of the research project was challenging, with only a small amount of data ultimately collected. This was due to a range of factors including limitations with data collection systems related to age, gender and geographical groupings. Third party data were also limited by the reports that the service providers' systems could produce, and by the information that could be freely provided to other organisations. In addition, women may have been engaging services for other issues, such as financial counselling or health issues, and the housing issue may not have been identified and therefore recorded.

- Officers in local government may not have the specialist knowledge required to undertake research into a hidden social issue. For this research, the City of Boroondara initiated a working relationship and research partnership with the University of Monash, Healthy Ageing Research Unit (HARU). This partnership provided the specialist knowledge, support and experience of HARU as part of the research team in the project design, development of the data collection methods, and analysis of the findings. HARU's knowledge was crucial for this research given the 
hidden nature of the issue and the sensitivity of interviewing older women who were homeless or at risk of homelessness.

- Researching a hidden social issue can be time consuming. As the Social Planning Unit at the City of Boroondara was leading the project, significant officer time was allocated towards the project. In addition, a Masters of Community Psychology student participated in the research. Members of the Project Working Group also spent a considerable amount of time assisting with the recruitment of older women for the interviews and reflecting on the findings of the research.

\section{The benefits of undertaking research into a hidden issue}

There are benefits of undertaking research in a local government area into a hidden issue. One benefit is the ability to access expertise and local demographic and qualitative data to support anecdotal reports into the issue. In the case of homelessness, research at the local government area it also affords opportunities to assess concomitant local issues around health and other service provisions affecting this social issue. This information can then be used by councils and service providers to inform policy, planning and service delivery at the local level.

For the City of Boroondara, raising awareness within the community about the issue was another benefit of undertaking research into a hidden issue. As this research found, community awareness of the issue of homelessness in older women was low. By widely promoting the project and data collection methods, awareness about the issue was raised and the issue was no longer as hidden as it was before the project commenced. This may assist people who are affected by the issue to seek help. It may also encourage community members to identify people who need assistance.

\section{Recommendations arising from the research project}

The research project identified four key areas for future work. These are to:

- Inform residents, businesses, local services and all levels of government on issues that impact on older women and contribute to homelessness and the risk of homelessness

- Build the capacity of local services to identify and address issues that impact on older women and contribute to homelessness and the risk of homelessness 
- Promote services and resources that offer support to older women and their families on issues that impact on, and contribute to homelessness and the risk of homelessness

- Advocate on issues that impact on older women and contribute to homelessness and the risk of homelessness.

The key areas identified link to existing Council policies and strategies such as Creating an Age Friendly Boroondara 2009-14 (City of Boroondara 2009a), the Social Housing Policy 2008-11 (City of Boroondara 2008) and the Boroondara Public Health and Wellbeing Plan 2009-13 (City of Boroondara 2009b). As these documents or associated action plans are currently being redeveloped, the findings of this project will be incorporated into the review and redevelopment process.

The key areas identified also build on existing actions connected to positive ageing, community capacity building, and various other issues being addressed by services and in a range of forums. Existing networks and forums convened by Council, such as the Boroondara Aged Service Providers Association, were seen as opportunities to discuss the issues related to homelessness among older women. Such networks and forums would also provide opportunities to engage services and organisations not currently aware of issues around homelessness in older women. An annual meeting, rather than an ongoing Project Working Group, will be used to discuss the issues and identify emerging issues, and to continue connecting these to local and wider issues and directions.

\section{Conclusions}

Through this research it was found that there are challenges in undertaking research into 'hidden' issues at the local government level, including difficulties in recruiting participants and accessing supporting data. Other difficulties identified included accessing officers with the specialist knowledge and the time to complete the research.

The key recommendations arising from the research for local governments undertaking local research into hidden social issues are as follows:

- establish a Project Working Group of key stakeholders to inform the development of the research proposal, and assist in the data collection and analysis of the findings

- assign a dedicated project team that has the skills and expertise to undertake the research 
- enter into a partnership with a university or other expert bodies that are able to provide specialist knowledge on data collection methods and analysisemploy a range of data collection methods to ensure that the views of the community, as well as individuals directly affected by the issue, are captured

- develop a data collection tool to assist service providers to collect quantitative data about the issue

- widely publicise the project within the community to raise awareness of the issue and to assist with recruiting project participants.

Although researching a hidden issue can be challenging, the City of Boroondara found the process to be invaluable as it provided a greater understanding of the issue and how it can be addressed at the local level. It also assisted in raising awareness of the issue so that it is no longer as hidden as it was before the research commenced. As the municipality has an ageing population and the demand for affordable housing by older women is likely to grow, the Social Planning Unit at the City of Boroondara will continue to explore ways to incorporate the findings of the research into relevant Council policies and documents. It will also explore ways to raise awareness of the issue in the community to assist and prevent older women from entering homelessness.

\section{References}

ANGLICARE Sydney 2011, Home truths: impacts of housing security on women across the life course, ANGLICARE Sydney, Sydney.

Australian Bureau of Statistics (ABS) 2011, Census of Population and Housing: Sex, Age and Local Government Area by Family Composition, ABS, Canberra.

ABS 2013a, Boroondara (C) (Statistical Local Area), Quickstats, ABS, viewed 2 May 2013, $<$ http://www.censusdata.abs.gov.au/census_services/getproduct/census/2011/quickstat/L GA21110>.

ABS 2013b, 'Table 2: local government area, indexes, SEIFA 2011', in Census of Population and Housing: Socio-Economic Indexes for Areas (SEIFA), Australia, 2011, cat. no. 2033.0.55.001, ABS, Canberra, viewed 9 May 2013, <http://www.abs.gov.au/AUSSTATS/abs@.nsf/DetailsPage/2033.0.55.0012011>.

Australian Government 2008, The Road Home - The Australian Government White Paper on Homelessness, Department of Social Services, Australian Government, Canberra. 
Bridge, C., Davy, L., Judd, B., Flatau, P., Morris, A. \& Phibbs, P. 2011, Age-specific housing and care for low to moderate income older people, Australian Housing and Urban Research Institute, Melbourne, viewed 8 May 2013, $<$ http://www.ahuri.edu.au/publications/projects/p70589/>.

Chamberlain, C. \& MacKenzie, D. 2006, Counting the Homeless 2006, cat. no. 2050.0, ABS, Canberra.

City of Boroondara 2008, City of Boroondara Social Housing Policy 2008-11, City of Boroondara, $\quad$ Melbourne, viewed 8013 , $<$ http://www.boroondara.vic.gov.au/residents/health-wellbeing/housing-homelessness >.

City of Boroondara 2009a, Creating an Age Friendly Boroondara: Active ageing and community participation 2009 - 2014, City of Boroondara, Melbourne.

City of Boroondara 2009b, Public Health and Wellbeing Plan 2009-13, City of Boroondara, Melbourne.

City of Boroondara 2010, Older women and homelessness, a literature review, City of Boroondara, Melbourne.

Department of Human Services 2011a, Rental Report June quarter 2011, Department of Human Services, Melbourne.

Department of Human Services 2011b, Summary of Housing Assistance Programs 2009-10, Department of Human Services, Melbourne.

Department of Human Services 2011c, Public housing waiting and transfer list December 2011, Department of Human Services, Melbourne.

Forecast.id 2011, Population Forecasts for the City of Boroondara, Forecast.id, Melbourne, viewed 8 May 2013, <http://forecast.id.com.au/boroondara>.

McFerran, L. 2010, It could be you: female, single, older and homeless, Homelessness NSW, Sydney.

National Housing Supply Council 2011, State of Supply Report 2010, Australian Government, Canberra.

Swinburne University of Technology 2013, Housing in Victoria: Median housing prices (real), Housing in Victoria, viewed 2 May 2013, $<$ http://www.housinginvictoria.com.au/Results.aspx $>$.

Victorian Government 2011, Victorian Homelessness Action Plan 2011-15, Australian Government, Melbourne, viewed 2 May 2013, <http://www.dhs.vic.gov.au/about-thedepartment/documents-and-resources/reports-publications/victorian-homelessness-actionplan-2011-2015>. 
Westmore, T. \& Mallett, S. 2011, Ageing in what place? The experiences of housing crisis and homelessness for older Victorians, Final Report, Hanover Welfare Services, Melbourne. 